\title{
Má oclusão Classe III de Angle com discrepância ântero-posterior acentuada*
}

\author{
Marcos Alan Vieira Bittencourt ${ }^{\star \star}$
}

\begin{abstract}
Resumo
A má oclusão Classe III de Angle é caracterizada por uma discrepância dentária ântero-posterior, que pode ou não estar acompanhada por alterações esqueléticas. Em geral, o aspecto facial fica bastante comprometido, sendo justamente esse fator, na maioria das vezes, que motiva o paciente a procurar pelo tratamento. Este caso foi apresentado à Diretoria do Board Brasileiro de Ortodontia e Ortopedia Facial (BBO), representando a categoria 4, ou seja, uma má oclusão com discrepância ântero-posterior acentuada, Classe III, com ANB menor ou igual a $-2^{\circ}$, como parte dos requisitos para a obtenção do título de Diplomado pelo BBO.
\end{abstract}

Palavras-chave: Má oclusão Classe III de Angle. Mordida cruzada. Ortodontia corretiva.

\section{HISTÓRIA E ETIOLOGIA}

O paciente se apresentou para o exame inicial aos 27 anos, com bom estado geral de saúde. Sua história médica e odontológica não possuía registros significativos, tendo contraído sarampo e catapora durante a infância. Não era portador, nem relatou ter sido, de qualquer hábito anormal de pressão. Sua queixa principal estava relacionada à presença de mordida cruzada na região anterior e à protrusão do lábio inferior, o que comprometia sua estética facial (Fig. 1). Em relação às atividades funcionais, não apresentava alterações no posicionamento lingual durante os movimentos de mastigação, deglutição ou fonação. Embora haja, em geral, um componente hereditário na determinação de alguns desses fatores, a etiologia, neste caso, pareceu ser multifatorial.

\section{DIAGNÓSTICO}

Apresentava uma desarmonia esquelética significativa, com ANB igual a $-3^{\circ}\left(\mathrm{SNA}=80^{\circ}\right.$ e SNB $=83^{\circ}$ ), um crescimento mandibular deficiente no sentido vertical $\left(\mathrm{FMA}=30^{\circ}\right.$ e eixo $\left.\mathrm{Y}=59^{\circ}\right)$ e a maxila levemente retruída em relação à mandíbula e à base do crânio (âng. conv. $=-4^{\circ}$ ). Essas observações podem ser melhor avaliadas na figura 4.

Quanto ao aspecto dentário, como pode ser observado na figura 2, possuía uma má oclusão Classe III de Angle, subdivisão direita, inclinação vestibular dos incisivos superiores e verticalização dos inferiores, linha média inferior desviada $4 \mathrm{~mm}$ à esquerda, sobressaliência de $-1 \mathrm{~mm}$, sobremordida de $2 \mathrm{~mm}$, mau posicionamento individual de alguns dentes, mordida cruzada no 16 e na região anterior, ausência do 36 e migração para distal

* Relato de caso clínico, categoria 4, aprovado pelo Board Brasileiro de Ortodontia e Ortopedia Facial (BBO).

** Doutor e Mestre em Ortodontia pela UFRJ. Professor Adjunto de Ortodontia da UFBA. Diplomado pelo Board Brasileiro de Ortodontia e Ortopedia Facial. 
com giroversão dos dentes 34 e 35.

Vale ressaltar que, com o objetivo de avaliar se a mordida cruzada presente na região anterior apresentava algum componente funcional, observou-se o padrão de fechamento do paciente, que não apresentou deslizes, ou seja, a posição de relação cêntrica era bastante próxima à posição de máxima intercuspidação.

$\mathrm{Na}$ análise das radiografias periapicais (Fig. 3), foi possível comprovar a ausência do dente 36 e verificar que o paciente não apresentava qualquer alteração que comprometesse o tratamento ortodôntico.

Em relação ao perfil, apresentava desarmonia no terço inferior, com o lábio superior retruído e o inferior bastante protruído (Fig. 1, 4).

\section{OBJETIVOS DO TRATAMENTO}

$\mathrm{Na}$ maxila, buscou-se manter o posicionamento vertical, ântero-posterior e transverso, tanto da base óssea quanto da dentição.

$\mathrm{Na}$ mandíbula, por tratar-se de um paciente adulto, objetivou-se manter o posicionamento da base óssea, melhorando o relacionamento oclusal
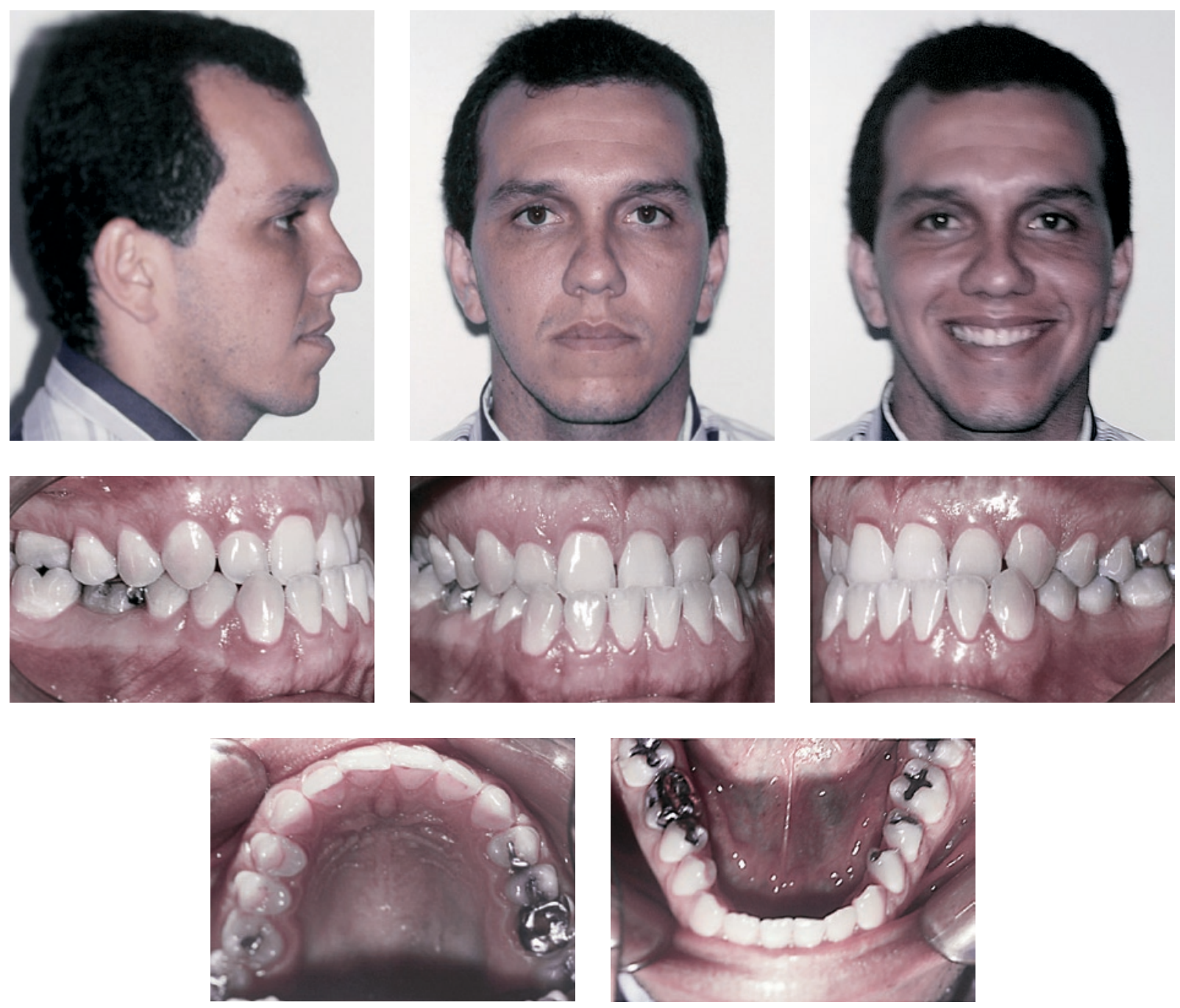

FIGURA 1 - Fotografias faciais e intrabucais iniciais. 

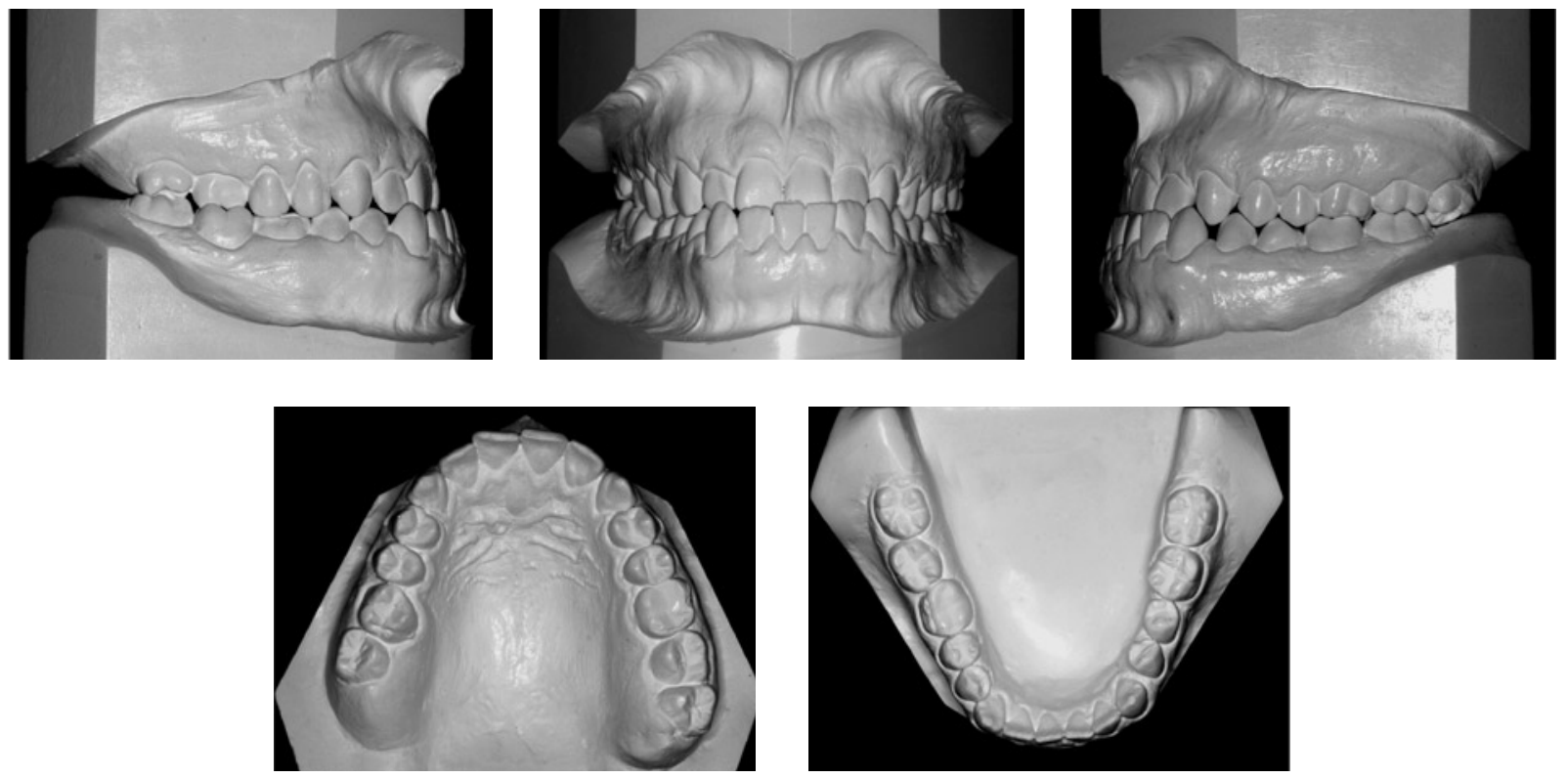

FIGURA 2 - Modelos iniciais.

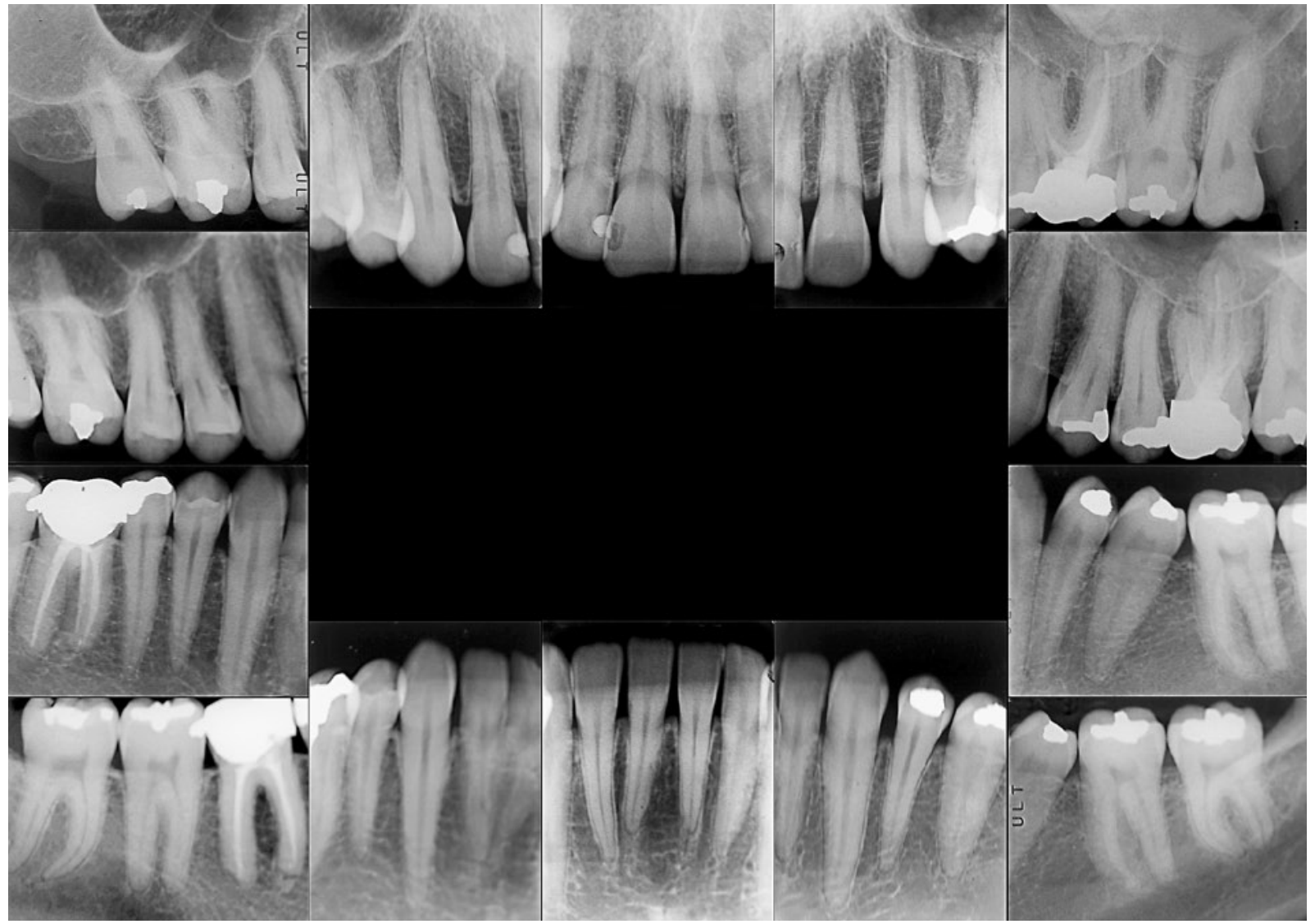

FIGURA 3 - Radiografias periapicais iniciais. 

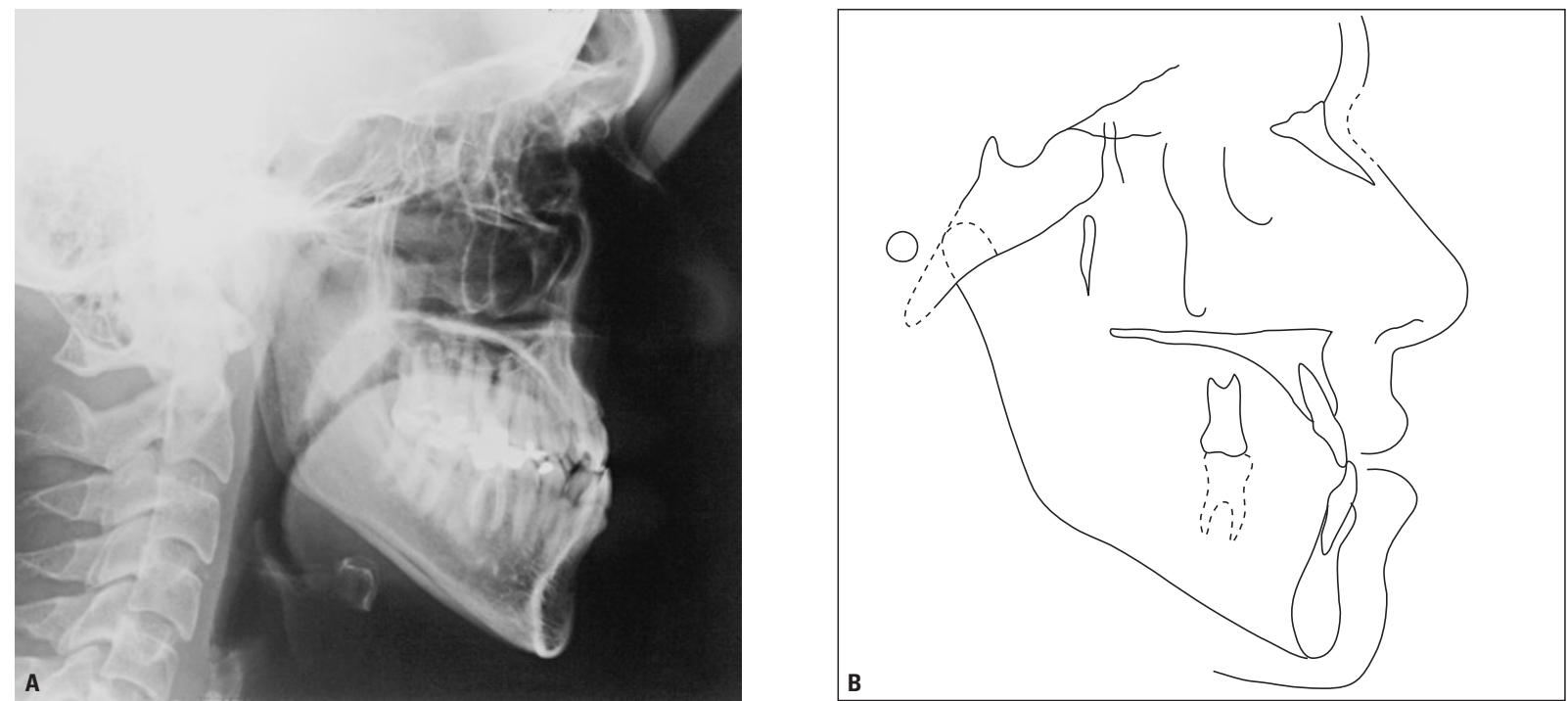

FIGURA 4 - Radiografia cefalométrica de perfil (A) e traçado cefalométrico (B) iniciais. Vale ressaltar que o molar inferior, traçado em pontilhado, representa o segundo molar do lado esquerdo, que foi registrado em função da ausência do primeiro molar.

com a correção da relação de Classe III de Angle, na região de caninos, no lado direito, e corrigindose a relação anterior com a retração dos incisivos. Com isso, esperava-se melhorar significativamente a estética, tanto dentária quanto facial, pela modificação do perfil do paciente com a retração do lábio inferior.

\section{PLANO DE TRATAMENTO}

Foram elaborados três planos de tratamento. $\mathrm{O}$ primeiro, envolvendo cirurgia ortognática. $\mathrm{O}$ segundo, com a exodontia do dente 46 , já excessivamente manipulado clinicamente. E o terceiro, com exodontia do dente 44. A cirurgia foi prontamente desconsiderada pelo paciente. Em relação ao tratamento somente ortodôntico, foi explicado ao paciente que esse seria mais longo com a exodontia do 46, pois o espaço criado estaria localizado em uma região mais posterior. Assim, optou-se, em conjunto, pela exodontia do 44 .

Planejou-se a colocação de aparelhagem ortodôntica superior e inferior, e $\operatorname{arcos} 0,014$ " a 0,020" para alinhamento e nivelamento. A relação de Classe III de Angle, do lado direito, nos molares, seria mantida. Nos caninos, para a correção des- sa relação, foi planejado o movimento total para distal do 43, utilizando os dentes posteriores inferiores do lado direito, amarrados conjuntamente (tie together), como unidade de ancoragem. Para a correção da linha média inferior, foi idealizada a movimentação dos dentes 42 e 41 para distal, e dos dentes 31 e 32 para mesial, individualmente, mantendo-se a mesma configuração de ancoragem. No lado esquerdo, a melhoria do posicionamento dos dentes 35, 34 e 33 seria realizada, também, dessa forma. Em seguida, arco 0,019" x 0,025" inferior com drop loop entre incisivos laterais e caninos, para retração dos incisivos. Para a finalização, $\operatorname{arcos} 0,019$ " x 0,025" superior e inferior com dobras de primeira e terceira ordens, individualizadas de acordo com a necessidade do caso. Após a fase de tratamento ativo, planejou-se utilizar placa de contenção superior com wraparound e, no arco inferior, barra intercaninos com fio 0,028 ".

\section{PROGRESSO DO TRATAMENTO}

Foram instalados anéis ortodônticos nos primeiros e segundos molares permanentes (superiores e inferiores) e no terceiro molar inferior esquerdo. Foi solicitada a exodontia do dente 44 e 
colados braquetes metálicos do tipo standard, sem torques ou angulações, de slot 0,022 " x 0,028 ", sistema Edgewise.

Seqüencialmente, foram instalados, no arco inferior, arcos de alinhamento e nivelamento de aço inoxidável 0,014" a 0,020", de secção redonda, além do arco 0,018" x 0,025", de secção retangular. A partir do arco 0,020" inferior, foi feito tie together do dente 47 ao 45 e instalado elástico em cadeia para a movimentação total do dente 43 para distal. Em seguida, esse foi também incluído na unidade de ancoragem e foi utilizado elástico em cadeia, individualmente, para a movimentação dos dentes 42, 41, 31 e 32, para o lado direito, até a correção da linha média, preservando o espaço remanescente entre os incisivos laterais e os caninos, em ambos os lados. No lado esquerdo, tie together nos dentes 38 e 37 e elástico em cadeia para correção do giro das unidades 35 e 34, além de leve movimentação do 33 para distal.

No arco superior, foram utilizados arcos de alinhamento e nivelamento de aço inoxidável 0,014" a 0,020", de secção redonda, e arco de finalização, também de aço inoxidável, 0,019” x 0,025”, de secção retangular, com dobras de primeira e terceira ordens individualizadas.

$\mathrm{Na}$ fase seguinte, no arco inferior, foi instalado arco de aço inoxidável 0,019” x 0,025”, de secção retangular, com alça em forma de gota (drop loop) na região entre os incisivos laterais e caninos, para a retração dos incisivos. Nesse momento, foi instituída mecânica intermaxilar de Classe III no lado direito, como reforço de ancoragem. Após o fechamento total dos espaços, foi utilizado arco de aço inoxidável 0,019" x 0,025", de secção retangular, com dobras de primeira e terceira ordens, individualizadas de acordo com a necessidade, para a finalização.

Após a verificação de que todos os objetivos pretendidos foram alcançados, a aparelhagem ortodôntica fixa foi removida, iniciando-se, então, a fase de contenção. Foi utilizada uma placa removível superior (wraparound) e uma barra intercaninos fixa inferior, confeccionada com fio de aço inoxidável
0,028 ", de secção redonda. Foi recomendada a utilização da placa de contenção superior durante 24 horas por dia, nos primeiros seis meses, 18 horas por dia, nos seis meses seguintes, 12 horas por dia, por mais seis meses e, em seguida, uso noturno.

\section{RESULTADOS DO TRATAMENTO}

Avaliando-se os registros finais do paciente, pode-se verificar que todos os objetivos pretendidos foram alcançados. Na maxila, foi mantido o posicionamento vertical, ântero-posterior e transverso da base óssea, tendo havido leve aumento no posicionamento ântero-posterior e na inclinação dos incisivos. Como pode ser visto na tabela 1 , o ângulo 1-NA sofreu modificação de $22^{\circ}$ para $25^{\circ}$ e o posicionamento linear dos incisivos (1-NA, mm) aumentou $2 \mathrm{~mm}$, passando de $6 \mathrm{~mm}$ para $8 \mathrm{~mm}$. Essa mudança foi intencional e benéfica para a melhoria do relacionamento ântero-posterior entre os incisivos superiores e inferiores.

Na mandíbula, foi mantido o posicionamento ântero-posterior da base óssea, tendo havido leve movimento posterior da região alveolar, acompanhando a movimentação dos incisivos. Isso resultou em discreta melhora na desarmonia esquelética, com redução do ângulo ANB (Steiner), de $-3^{\circ}$ para $-2^{\circ}$ (Tab. 1). Do ponto de vista dentário, corrigiu-se a relação de Classe III de Angle, na região dos caninos, no lado direito, e o cruzamento na região anterior, com a retração dos incisivos (Fig. $5,6)$. Como pode ser visualizado na figura 7 , houve discreto arredondamento apical nos incisivos inferiores, provavelmente decorrente da extensa movimentação a que foram submetidos. Pode-se observar, também, a melhoria na inclinação axial dos dentes 34 e 35 , inicialmente inclinados para distal.

Com a correção da protrusão inferior, houve melhora significativa da estética dentária, o que também refletiu na melhora do perfil facial, com a retração do lábio inferior, que passou de uma posição de $3 \mathrm{~mm}$ em relação à linha $\mathrm{S}$ (Steiner) para $1 \mathrm{~mm}$ (Fig. 5, 8). 

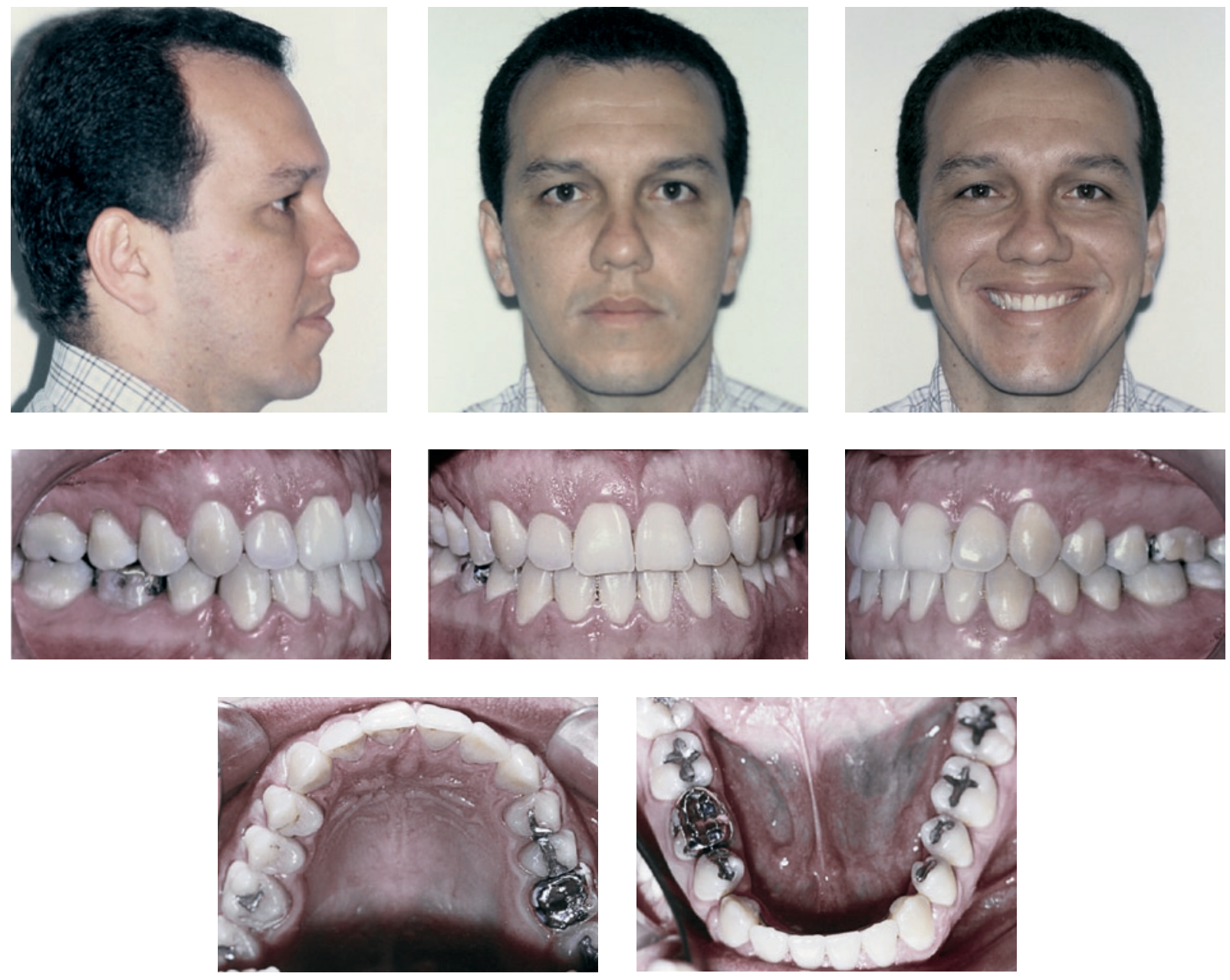

FIGURA 5 - Fotografias faciais e intrabucais finais.
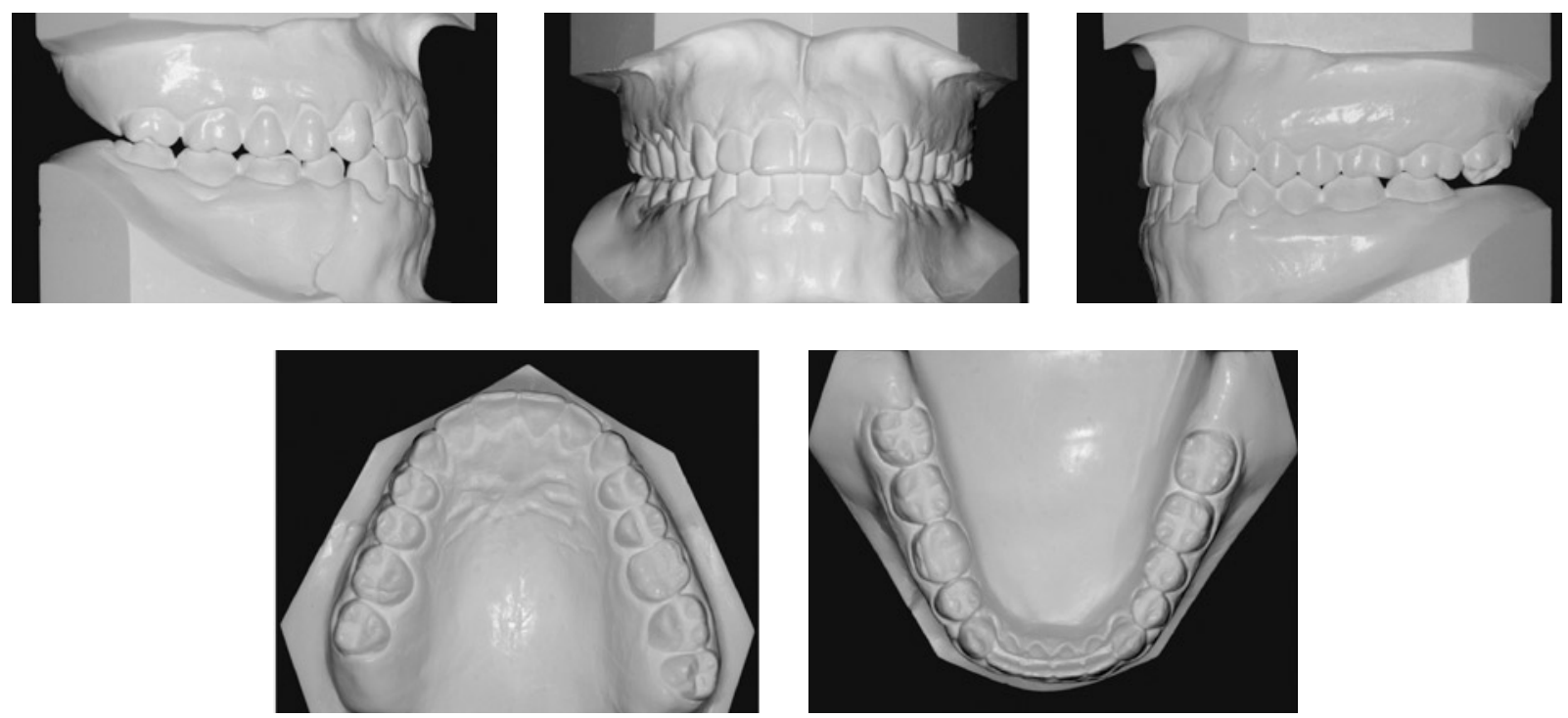

FIGURA 6 - Modelos finais. 


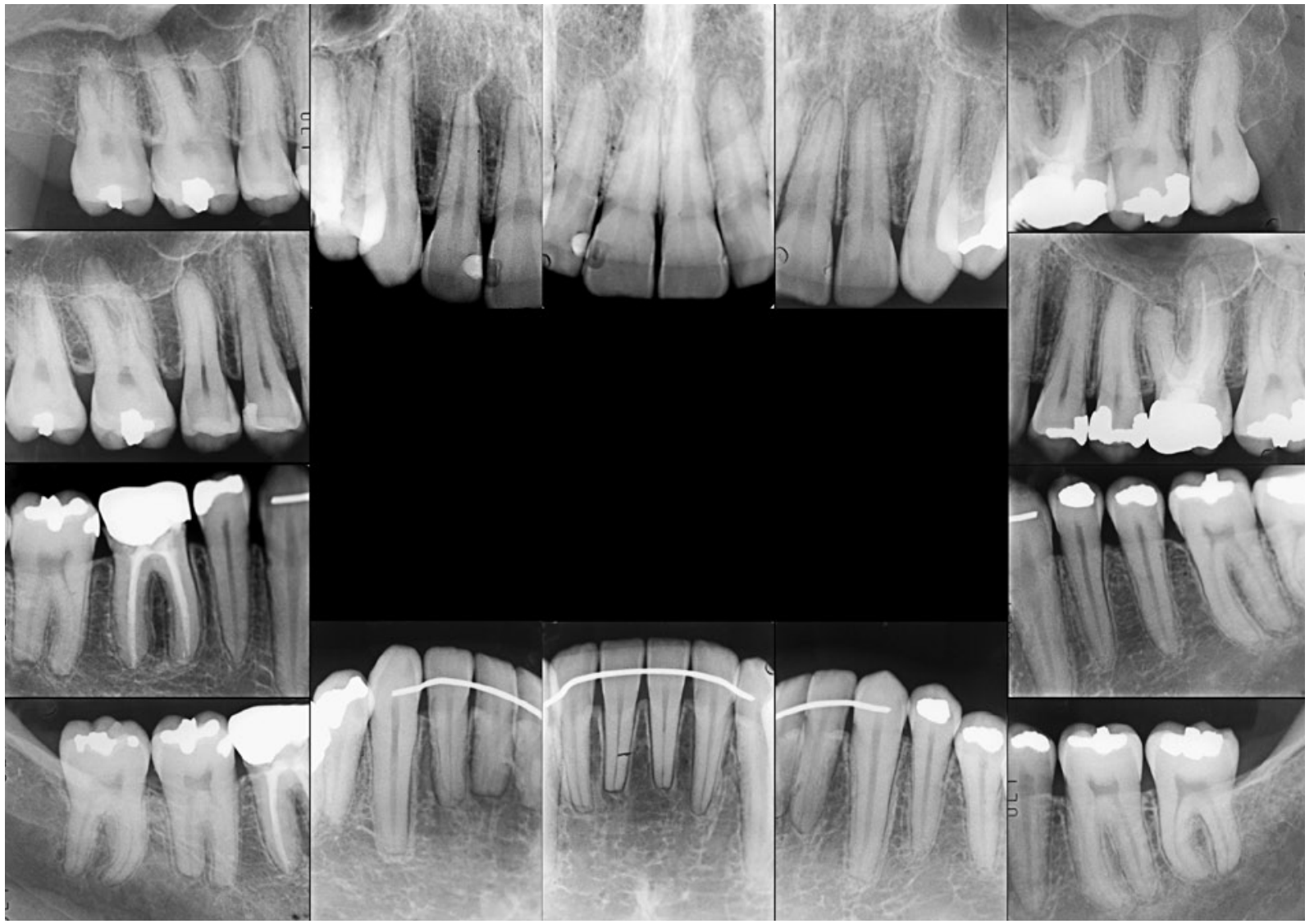

FIGURA 7 - Radiografias periapicais finais.
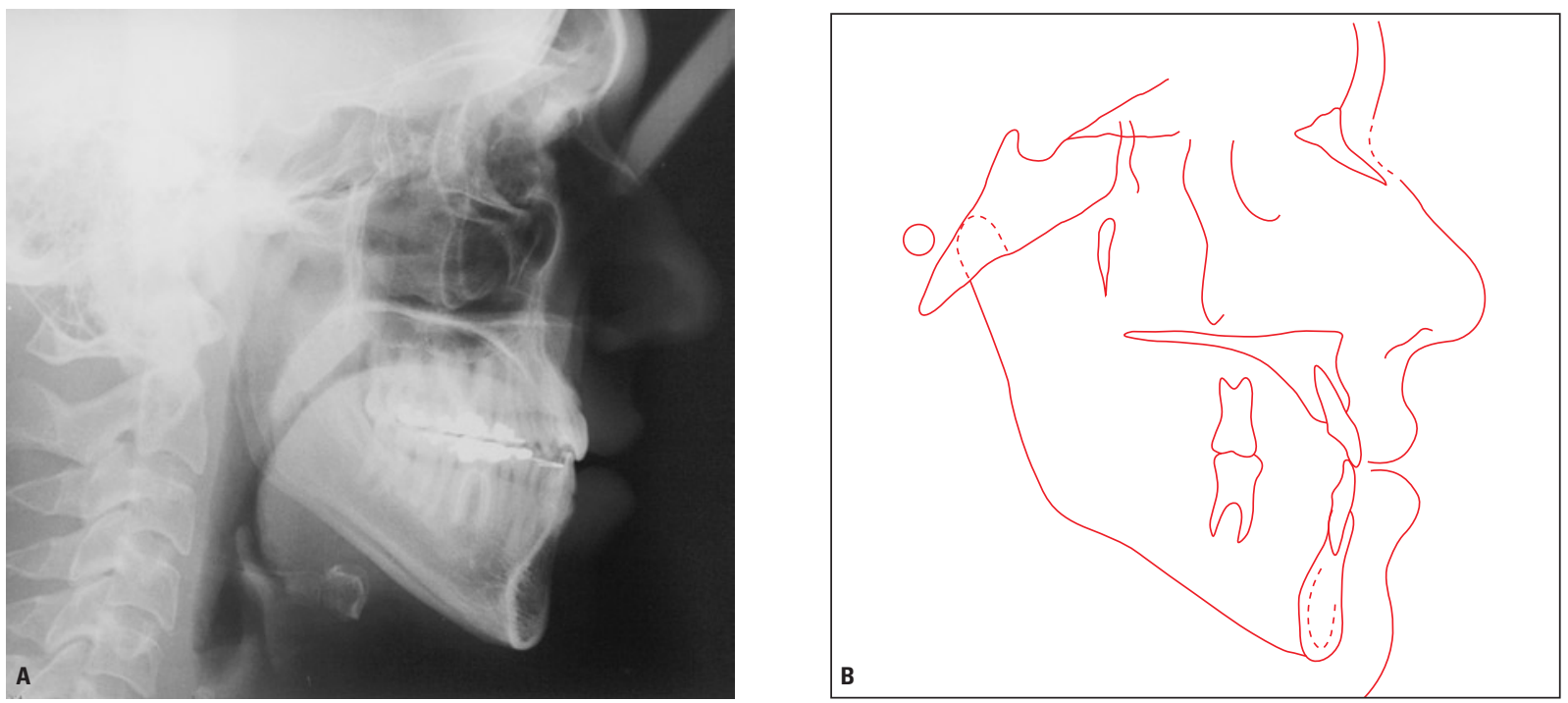

FIGURA 8 - Radiografia cefalométrica de perfil (A) e traçado cefalométrico (B) finais. 

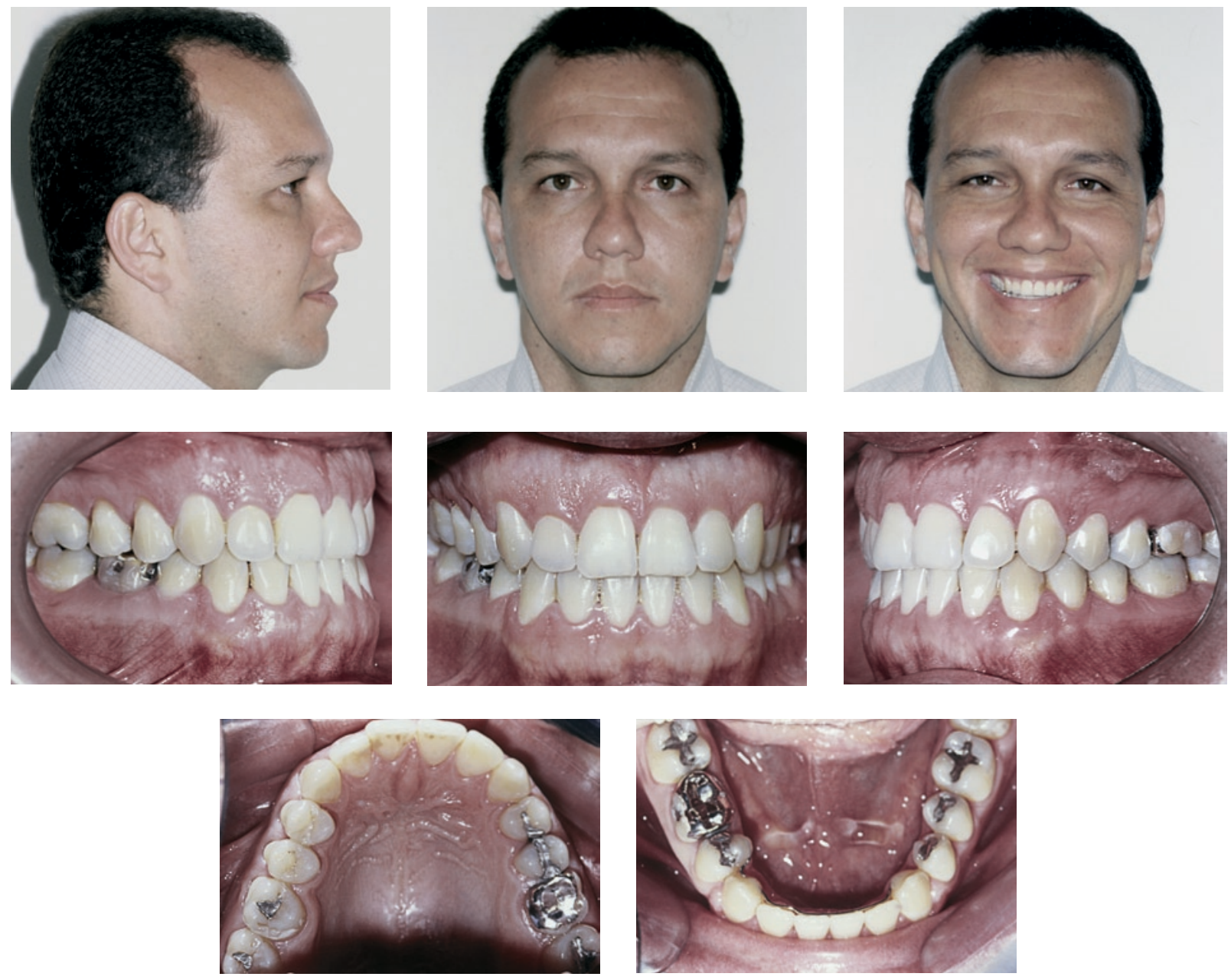

FIGURA 9 - Fotografias faciais e intrabucais de controle seis anos após o término do tratamento.
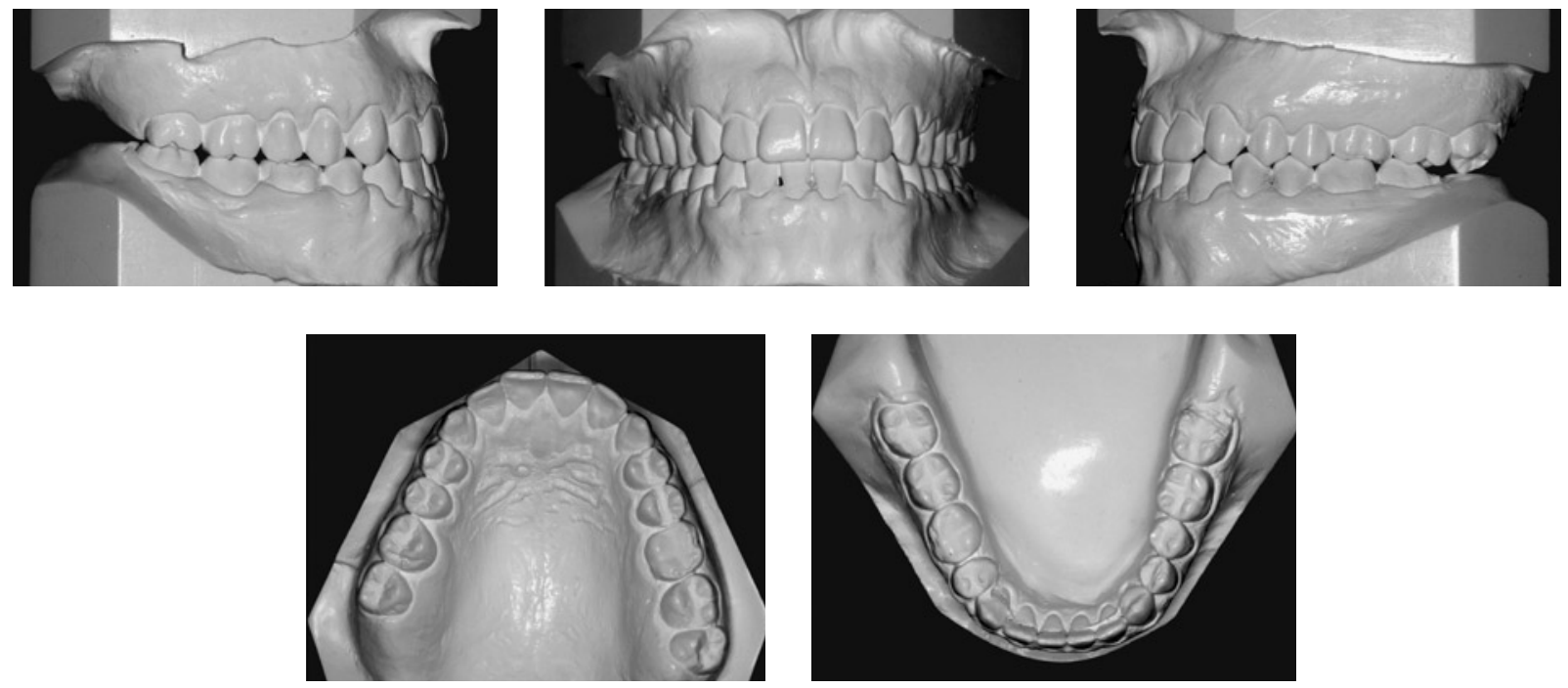

FIGURA 10 - Modelos de controle seis anos após o término do tratamento. 

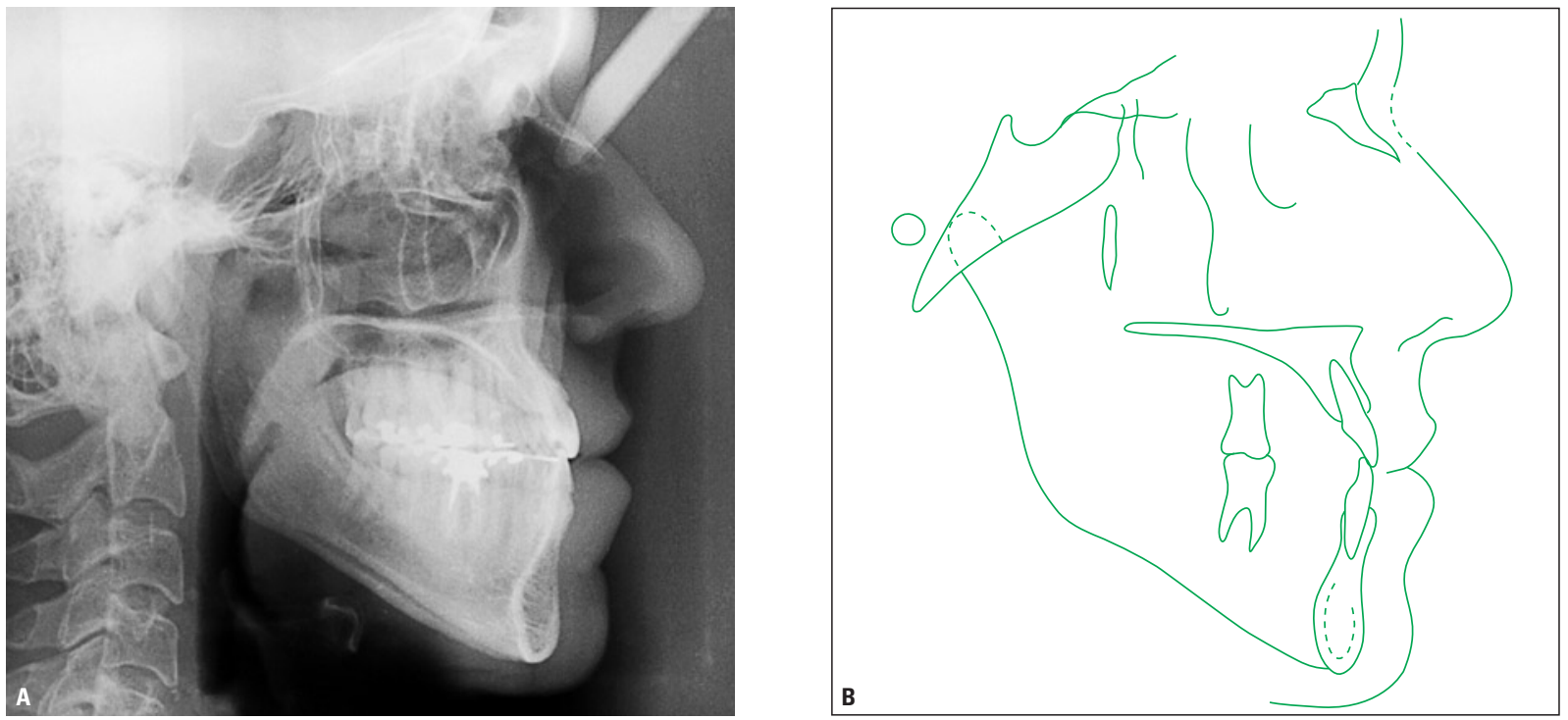

FIGURA 11 - Radiografia cefalométrica de perfil (A) e traçado cefalométrico (B) de controle seis anos após o término do tratamento.

Tabela 1 - Resumo das medidas cefalométricas.

\begin{tabular}{|c|c|c|c|c|c|c|}
\hline & MEDIDAS & NORMAL & $\begin{array}{l}\text { INICIAL } \\
\text { (A) }\end{array}$ & $\begin{array}{l}\text { FINAL } \\
\text { (B) }\end{array}$ & $\begin{array}{l}\text { CONTROLE } \\
6 \text { anos }\end{array}$ & $\begin{array}{c}\text { DIFERENÇA } \\
\text { A-B }\end{array}$ \\
\hline \multirow{8}{*}{$\begin{array}{c}\text { Padrão } \\
\text { Esquelético }\end{array}$} & SNA (Steiner) & $82^{\circ}$ & $80^{\circ}$ & $80^{\circ}$ & $80^{\circ}$ & $0^{\circ}$ \\
\hline & SNB (Steiner) & $80^{\circ}$ & $83^{\circ}$ & $82^{\circ}$ & $82^{\circ}$ & $1^{\circ}$ \\
\hline & ANB (Steiner) & $2^{\circ}$ & $-3^{\circ}$ & $-2^{\circ}$ & $-2^{0}$ & $1^{\circ}$ \\
\hline & Âng. conv. (Downs) & $0^{\circ}$ & $-4^{0}$ & $-4^{0}$ & $-4^{0}$ & $0^{\circ}$ \\
\hline & Eixo Y (Downs) & $59^{\circ}$ & $59^{\circ}$ & $60^{\circ}$ & $59^{\circ}$ & $1^{\circ}$ \\
\hline & Âng. facial (Downs) & $87^{\circ}$ & $79^{\circ}$ & $80^{\circ}$ & $80^{\circ}$ & $1^{\circ}$ \\
\hline & SN-GoGn (Steiner) & $32^{\circ}$ & $37^{\circ}$ & $36^{\circ}$ & $35^{\circ}$ & $1^{0}$ \\
\hline & FMA (Tweed) & $25^{\circ}$ & $30^{\circ}$ & $30^{\circ}$ & $30^{\circ}$ & $0^{\circ}$ \\
\hline \multirow{7}{*}{$\begin{array}{c}\text { Padrão } \\
\text { Dentário }\end{array}$} & IMPA (Tweed) & $90^{\circ}$ & $77^{\circ}$ & $67^{\circ}$ & $67^{\circ}$ & $10^{\circ}$ \\
\hline & 1-NA $\left({ }^{\circ}\right)$ (Steiner) & $22^{\circ}$ & $22^{\circ}$ & $25^{\circ}$ & $23^{\circ}$ & $3^{0}$ \\
\hline & 1-NA (mm) (Steiner) & $4 \mathrm{~mm}$ & $6 \mathrm{~mm}$ & $8 \mathrm{~mm}$ & $7 \mathrm{~mm}$ & $2 \mathrm{~mm}$ \\
\hline & 1-NB $\left({ }^{\circ}\right)$ (Steiner) & $25^{\circ}$ & $17^{\circ}$ & $7^{0}$ & $8^{\circ}$ & $10^{\circ}$ \\
\hline & 1-NB (mm) (Steiner) & $4 \mathrm{~mm}$ & $6 \mathrm{~mm}$ & $3 \mathrm{~mm}$ & $2 \mathrm{~mm}$ & $3 \mathrm{~mm}$ \\
\hline & $\begin{array}{l}\text { Âng. interincisal } \\
\text { (Downs) }\end{array}$ & $130^{\circ}$ & $142^{\circ}$ & $152^{\circ}$ & $152^{\circ}$ & $10^{\circ}$ \\
\hline & 1-APo (mm) (Ricketts) & $1 \mathrm{~mm}$ & $5 \mathrm{~mm}$ & $2 \mathrm{~mm}$ & $1 \mathrm{~mm}$ & $3 \mathrm{~mm}$ \\
\hline \multirow{2}{*}{ Perfil } & L.sup - linha S (Steiner) & $0 \mathrm{~mm}$ & $-3 \mathrm{~mm}$ & $-3 \mathrm{~mm}$ & $-3 \mathrm{~mm}$ & $0 \mathrm{~mm}$ \\
\hline & L.inf - linha S (Steiner) & $0 \mathrm{~mm}$ & $3 \mathrm{~mm}$ & $1 \mathrm{~mm}$ & $0 \mathrm{~mm}$ & $2 \mathrm{~mm}$ \\
\hline
\end{tabular}




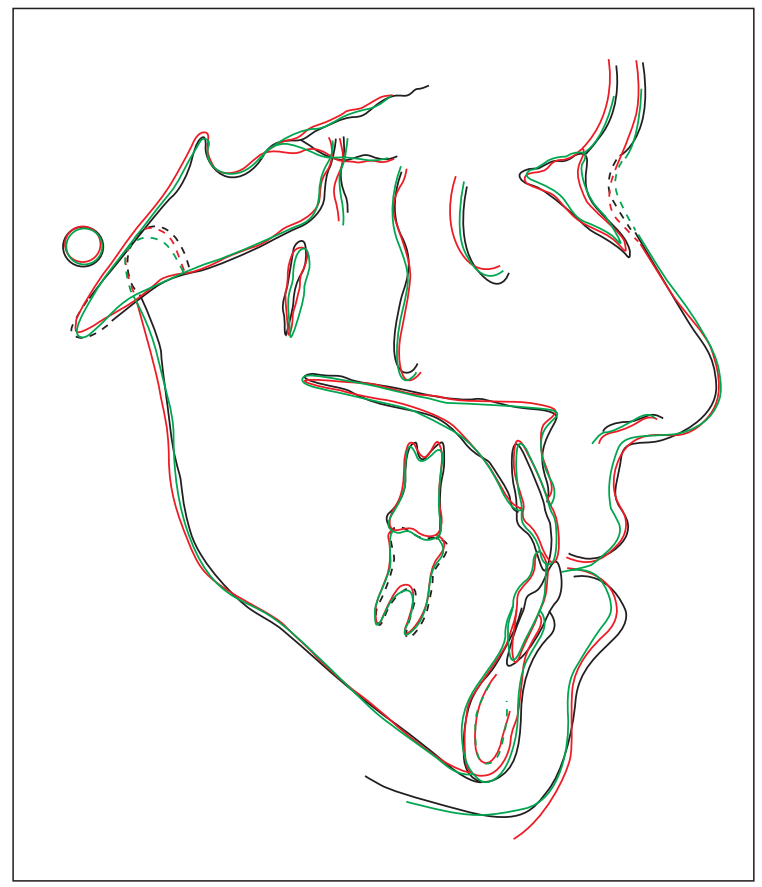

FIGURA 12 - Sobreposições dos traçados cefalométricos inicial, final e após seis anos.

\section{CONSIDERAÇÕES FINAIS}

A má oclusão Classe III de Angle, caracterizada por uma discrepância dentária ântero-posterior, é mais grave quando associada a uma desarmonia esquelética, que pode ser decorrente de uma deficiência maxilar, de um excesso mandibular ou de uma combinação de ambos. Essas alterações levam ao comprometimento do perfil facial, muitas vezes com conseqüências psicossociais.

As possibilidades terapêuticas para a correção dessa anomalia envolvem diversos fatores. Quando o paciente se encontra na fase pré-surto de crescimento puberal, uma abordagem precoce é indicada, como o uso de uma máscara facial para a realização de tração reversa da maxila, normalmente acompanhada de disjunção palatina ${ }^{1,3,5,6,7}$. Com essa abordagem, espera-se obter um posicionamento mais anterior da maxila, melhorando sua relação com a mandíbula e proporcionando uma oclusão satisfatória. Quando o paciente é adulto e, portanto, sem crescimento, o tratamento deve ser decidido entre os procedimentos de camuflagem, caso o comprometimento esquelético não seja excessivo ${ }^{2}$, e os ortodôntico-cirúrgicos clássicos, que podem envolver avanço de maxila, recuo de mandíbula ou uma combinação de ambos ${ }^{6}$. No caso relatado, o paciente, apesar de informado sobre os benefícios de um tratamento combinado com a cirurgia ortognática, optou pela camuflagem dentária, nesse caso com a exodontia do dente 44 e movimentação para posterior da região ântero-inferior. Conforme já relatado, o paciente também se mostrou contrário à exodontia do dente 46 , após informado de que essa opção implicaria em aumento na estimativa de duração do tratamento, pela necessidade de movimentação para distal dos dentes 45 e 44, individualmente, uma vez que o espaço criado estaria posicionado mais para posterior.

Do ponto de vista dentário, o paciente apresentava as relações molar e canino de Classe III, no lado direito. No lado esquerdo, a relação molar era de chave de oclusão, considerando a intercuspidação do primeiro molar superior com o segundo molar inferior, em função da perda do dente 36 , por cárie, durante a adolescência. Também por causa dessa perda, houve migração para distal dos pré-molares e canino inferiores do lado esquerdo, fazendo com que a relação canino também fosse de chave de oclusão. Com a exodontia do dente 44, pretendeuse, no lado direito, corrigir a relação de Classe III nos caninos e manter essa relação nos molares, preservando-se a posição mais mesializada do dente 46. Sabe-se que, dessa forma, o segundo pré-molar superior estabelece relação exclusivamente com o primeiro molar inferior, o que não é favorável para a preservação das estruturas periodontais daquele ${ }^{4,8}$. Por esse motivo, imediatamente após a remoção da aparelhagem fixa, o paciente foi encaminhado a um protesista, para que fosse feita uma avaliação da distribuição dos contatos oclusais e, onde necessário, realizasse ajustes, com o objetivo de preservar a integridade de todos os dentes, especialmente do 15 . Isso foi realizado e, com esse cuidado, pretendeu-se 
obter maior segurança em relação à estabilidade do resultado obtido.

Como pode ser observado nos registros obtidos seis anos após o término do tratamento ativo (Fig. 9, 10, 11) e nas sobreposições dos traçados cefalométricos inicial, final e controle (Fig. 12), o resultado observado após a remoção da apare- lhagem ortodôntica permaneceu inalterado, o que comprova a efetividade da terapia instituída.

\title{
Angle Class III malocclusion with severe anteroposterior disharmony
}

\begin{abstract}
Angle Class III malocclusion is characterized by an anteroposterior dental discrepancy which may or may not be accompanied by skeletal changes. In general, distressed by a significantly compromised facial aspect, patients tend to seek treatment. This case was presented to the Brazilian Board of Orthodontics and Facial Orthopedics (BBO), as representative of Category 4, i.e., a malocclusion with severe anteroposterior discrepancy, Class III, and ANB Angle equal to or smaller than $-2^{\circ}$, as part of the requirements for obtaining the BBO Diploma.
\end{abstract}

Key words: Angle Class III. Crossbite. Corrective Orthodontics.

\section{REFERÊNCIAS}

1. BACCETTI, T.; McGILL, J. S.; FRANCHI, L.; MCNAMARA, J. A.; TOLLARO, I. Skeletal effects of early treatment of Class III malocclusion with maxillary expansion and face-mask therapy. Am. J. Orthod. Dentofacial Orthop., St. Louis, v. 113, no. 3, p. 333-343, Mar. 1998.

2. DALE, H. C. Morphologic skeletal asymmetry, with a Class III skeletal discrepancy, treated without surgical intervention. World J. Orthod., Carol Stream, v. 6, no. 4, p. 391-397, Winter 2005.

3. JIANG, J.; LIN, J.; JI, C. Two-stage treatment of skeletal Class III malocclusion during the early permanent dentition. Am. J. Orthod. Dentofacial Orthop., St. Louis, v. 128, no. 4 , p. 520-527, Oct. 2005

4. $\mathrm{KOKICH}, \mathrm{V}$. G.; KOKICH, V. O. Congenitally missing mandibular second premolars: clinical options. Am. J. Orthod. Dentofacial Orthop., St. Louis, v. 130, no. 4, p. 437-444, Oct. 2006.
Enviado em: novembro de 2008 Revisado e aceito: dezembro de 2008 